\title{
Comparison Between the Polymerase Chain Reaction-Based Screening and the Southern Blot Methods for Identification of Fragile X Syndrome
}

\author{
Karen M. Carvalho Curtis-Cioffi, Debora Aparecida Rodrigueiro, ${ }^{2}$ Valter Curi Rodrigues, ${ }^{3}$ \\ Regina M. Barretto Cicarelli, ${ }^{4}$ and Raquel Mantuaneli Scarel-Caminaga ${ }^{1}$
}

The fragile X syndrome (FXS), the most common cause of hereditary mental retardation, is caused by expansions of CGG repeats in the FMR1 gene. The gold-standard method to diagnose FXS is the Southern blot (SB). Because SB is laborious and costly, some adaptations in the polymerase chain reaction (PCR) method have been utilized for FXS screening. A previous PCR-based screening method for FXS identification utilizing small amounts of DNA was reported as simple and efficient. The aim of this study was to reproduce the mentioned PCR-based screening method for identification of expanded alleles of the FMR1 gene in Brazilian individuals and to investigate the efficiency of this method in comparison with SB. Utilizing the enzyme Expand Long Template PCR System, 78 individuals were investigated by that PCR-based screening method for FXS identification. Conclusive results were obtained for 75 samples. Considering all the allelic forms of FXS (normal [NL], premutation $[\mathrm{PM}]$, and full-mutation [FM]), the comparison of the PCR-based screening method with SB demonstrated $100 \%$ of accuracy, sensitivity, and specificity. However, when the PM and the FM were analyzed separately from each other, but together with the NL allele, the accuracy, sensitivity, and specificity decreased (to 42.9\%-97.4\%). We concluded that the PCR-based screening method was reproducible and capable of identifying all different FXS alleles, but because the differentiation between the PM and the FM alleles was not accurate, SB is still the gold-standard method for the molecular diagnosis of FXS.

\section{Introduction}

$\mathbf{T}$ He Fragile $X$ Syndrome (FXS) is the most common inherited cause of intellectual disabilities and the most common single genetic cause of autism (Hagerman et al., 2008). This is occurred by the instability and expansion of CGG repeats in the $5^{\prime}$-untranslated region (5'-UTR) of exon 1 of the FMR1 gene together with the occurrence of hypermethylation (Verkerk et al., 1991). The CGG-repeat element is polymorphic, varying in general from 5 to 44 repeats in the normal (NL) range, from 45 to 54 repeats in the gray zone, from 55 to 200 repeats in the premutation (PM) range, and over 200 CGG repeats in the full-mutation (FM) range (Crawford et al., 2001; Hagerman and Hagerman, 2004). Expansion to the FM occurs when PM alleles are transmitted maternally to offspring (Coffee et al., 2009).

Many techniques for identification of FXS have been reported in the literature, among them, molecular tests (Rous- seau et al., 1991; Haddad et al., 1996; Hamdan et al., 1997; Panagopoulos et al., 1999; Saluto et al., 2005; Dahl et al., 2007; Rosales-Reynoso et al., 2007; Dodds et al., 2009; Chen et al., 2010; Filipovic-Sadic et al., 2010). Two main diagnostic techniques have been developed for the DNA-based diagnosis of FXS: Southern blot (SB) and polymerase chain reaction (PCR) (Sofocleous et al., 2009). SB is considered the gold-standard method for diagnosis of FXS, in spite of it is laborious and costly.

The use of PCR for FXS screening suffers some methodological difficulties, such as amplification of large-sequence rich-oin $C$ and $G$ nucleotides, which led several researchers to propose modifications in this method (Haddad et al., 1996; Hamdan et al., 1997; Panagopoulos et al., 1999; Saluto et al., 2005; Dahl et al., 2007; Rosales-Reynoso et al., 2007). Tassone et al. (2008) reported a PCR-based screening method for FXS that seems to be revolutionary, because only PCR would solve most of the suspicious cases of the syndrome (PM or FM allele carriers in both genders, including mosaics).

\footnotetext{
${ }^{1}$ Department of Morphology, UNESP, Univ Estadual Paulista, School of Dentistry in Araraquara, Araraquara, Brazil.

${ }^{2}$ Department of Morphology and Pathology, PUC-SP, Pontifical Catholic University, School of Medical and Health Sciences, Sorocaba, Brazil.

${ }^{3}$ Department of Medicine, UNIARA, University Center Araraquara, Araraquara, Brazil.

${ }^{4}$ Department of Biological Sciences, UNESP, Univ Estadual Paulista, School of Pharmaceutical Sciences, Araraquara, Brazil.
} 
Considering the potential usefulness of the PCR-based screening method described by Tassone et al. (2008) for rapid identification of expanded alleles of the FMR1 gene, the aim of this study was utilize it in Brazilian individuals and verify its efficiency through analysis of accuracy, sensitivity, and specificity in comparison with SB.

\section{Materials and Methods}

\section{Samples}

DNA samples from 78 individuals, being 40 males and 38 females, some of them suspicious of FXS and also relatives, mainly their mothers (6 in total) were used in the current study. These 62 samples were provided by Dr. Débora Aparecida Rodrigueiro from the School of Medical Sciences and Health (FCMS / PUC-SP) and by Dr. Angela Maria ViannaMorgante from the Biosciences Institute of São PauloUSP. The other 16 samples were collected from patients referred by Dr. Valter Curi Rodrigues, from the University Center of Araraquara (UNIARA). This study was approved by the Committee for Ethics Affairs of UNESP-São Paulo State University, Faculty of Pharmaceutical Sciences (Protocol number 24/2008).

\section{Molecular analysis}

Drops of peripheral blood from each patient were collected with an FTA card (Whatman, Inc.). A disk $1.5 \mathrm{~mm}$ in diameter was removed by punch from each dried blood spot, and the proceedings of card purification were made according to Tassone et al. (2008). Each purified sample was numbered by another participant researcher, so that the study could be conducted in a blind way.

Afterward, the PCR-based screening method for FXS identification described by Tassone et al. (2008) was developed. The first and second PCR reactions were performed using the master mix containing $0.33 \mu \mathrm{M}$ of each $\mathrm{c}$ and $\mathrm{f}$ primers (Fu et al., 1991), $500 \mu \mathrm{M}$ of dNTPs, $2.2 \mathrm{M}$ of betaine (USB), and one disk of 1.5-mm FTA card. The PCR cycling conditions included initial denaturation at $98^{\circ} \mathrm{C}$ for $10 \mathrm{~min}$; $68^{\circ} \mathrm{C}$ for $2 \mathrm{~min}$ (hot start, with the addition of $0.5 \mathrm{U}$ of Expand Long Template PCR System [Roche Diagnostics] enzyme with buffer $2[1 \times])$, followed by 10 cycles at $97^{\circ} \mathrm{C}$ for $35 \mathrm{~s}, 64^{\circ} \mathrm{C}$ for $35 \mathrm{~s}$, and $68^{\circ} \mathrm{C}$ for $4 \mathrm{~min} ; 25$ cycles at $97^{\circ} \mathrm{C}$ for $35 \mathrm{~s}, 64^{\circ} \mathrm{C}$ for $35 \mathrm{~s}$, and $68^{\circ} \mathrm{C}$ for $4 \mathrm{~min}$, plus a 20 -s increment for each cycle; and a final extension at $68^{\circ} \mathrm{C}$ for $10 \mathrm{~min}$.

Because some information such as enzyme concentration and hot start details was not observed in the article published by Tassone et al. (2008), the PCR method had to be standardized by our group. Here, we utilized $0.5 \mathrm{U}$ of the Expand Long Template PCR System (Roche Diagnostics) enzyme and the hot start, as was detailed above.

The PCR products were electrophoresed at $6 \mathrm{~V} / \mathrm{cm}$ for $60 \mathrm{~min}$ on a $2 \%$ TBE $1 \times$ agarose gel containing ethidium bromide. The gels were visualized on a transilluminator and photographed in the GDS 8000 System (UVP). The expected constant region of the PCR product presents an amplicon of $221 \mathrm{bp}$ (i.e., excluding the expanded CGG repeats).

Samples that did not produce a band in the first PCR were subjected to a secondary PCR screen with the c primer and the CGG-chimeric primer described by Tassone et al. (2008) (Fig. 1). In that second PCR, were used the same reagents and cycling conditions mentioned above.

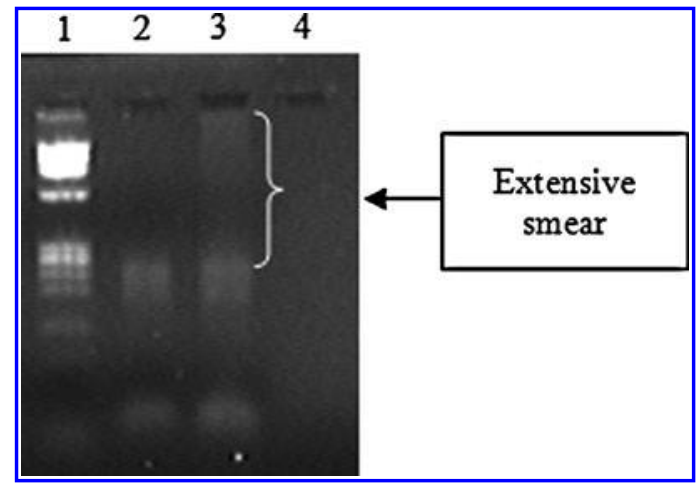

FIG. 1. Detection of expanded alleles using CGG-targeting polymerase chain reaction (PCR) primer; $2 \%$ agarose gel. Lane 1: DNA size marker PhiX 174 HaeIII (New England). Lane 2: Sample of individual with normal (NL) allele for the FXS. Lane 3: Sample of individual with fragile $X$ syndrome (FXS) full-mutation (FM) allele (an extensive smear is displayed in the presence of the allele). Lane 4: Control negative.

In addition, as suggested by Tassone et al. (2008), to eliminate the hot start procedure (necessary when utilizing the Expand Long Template PCR System enzyme), we also made efforts to standardize the utilization of the FastStart Taq DNA Polymerase (Roche Diagnostic) enzyme. However, important details that are necessary for the proper use of this polymerase were absent in the aforementioned report, such as (1) which buffer (and its concentration) had to be used; (2) how many enzyme units should be required; and (3) which cycling conditions should be utilized. Therefore, the lack of all this information offered difficulties for the success in reproducing the PCR-based screening method for FXS described by Tassone et al. (2008), and then we tried to adapt it. After some attempts, the best conditions reached by using the FastStart Taq DNA Polymerase enzyme for the first and second PCRs were a master mix containing $0.33 \mu \mathrm{M}$ of each $\mathrm{c}$ and $\mathrm{f}$ primers (Fu et al., 1991), $0.5 \mathrm{U}$ of the enzyme with buffer $2(1 \times)$ without $\mathrm{MgCl}_{2}, 2.25 \mathrm{mM}$ of $\mathrm{MgCl}_{2}, 500 \mu \mathrm{M}$ of dNTPs, $2.2 \mathrm{M}$ of betaine (USB), and a disk of 1.5-mm FTA card. The PCR cycling conditions were as follows: initial denaturation at $98^{\circ} \mathrm{C}$ for $10 \mathrm{~min}$, followed by 10 cycles at $97^{\circ} \mathrm{C}$ for $35 \mathrm{~s}, 64^{\circ} \mathrm{C}$ for $35 \mathrm{~s}$, and $72^{\circ} \mathrm{C}$ for $4 \mathrm{~min} ; 25$ cycles at $97^{\circ} \mathrm{C}$ for $35 \mathrm{~s}, 64^{\circ} \mathrm{C}$ for $35 \mathrm{~s}$, $72^{\circ} \mathrm{C}$ for $4 \mathrm{~min}$ plus a 20 -s increment for each cycle; and a final extension at $72^{\circ} \mathrm{C}$ for $10 \mathrm{~min}$. PCR products were electrophoresed at $6 \mathrm{~V} / \mathrm{cm}$ for $60 \mathrm{~min}$ on a $2 \%$ TBE $1 \times$ agarose gel containing ethidium bromide.

Concomitantly, to analyze the efficiency of the PCR-based screening method for FXS identification, all the samples were also submitted to FXS diagnosis by the SB method, which were performed by an outsourcing laboratory (using the probe StB12.3 and enzymatic digestion with EcoRI and EagI) (Mingroni-Netto et al., 1996).

After obtaining the results of the PCR-based screening method for FXS, they were compared, for each patient, with the SB results (gold-standard method). Contingency tables $(2 \times 2)$ were generated to assess the efficiency of identification of the FXS alleles by the PCR method described by Tassone et al. (2008). Accuracy, specificity, and sensibility were calculated utilizing the BioEstat v. 5.0 (Ayres et al., 2007). 


\section{Results}

Samples selected to amplify in the in the secondary PCR gave products as showed in the Figure 1. An extensive smear was produced with the chimeric primer when an expanded allele was present (lane 3), but no smear was visible in the presence of the NL allele (lane 2). These results demonstrate that we were able to reproduce the PCR-based screening method for FXS identification from Tassone et al. (2008) when utilizing the Expand Long Template PCR System enzyme.

In regard to the standardization of the Tassone et al. (2008) method using the FastStart Taq DNA Polymerase, we obtained success in amplifying the first PCR (data not shown), but for the second PCR, in spite of numerous attempts, only inconclusive results were achieved (Fig. 2).

Consequently, we decided to adopt the Tassone et al. (2008) PCR-based screening method for FXS identification with the Expand Long Template PCR System enzyme. A total of 78 samples from female and male subjects were analyzed. Samples from NL and PM females gave results consistent with that previous report for the first and second PCR (Fig. 3). From the 78 individuals investigated, conclusive results were obtained for 75 samples $(96.2 \%)$.

When the results of FXS diagnosed by the SB (gold standard) method were supplied by the outsourcing laboratory, they could be confronted with those results achieved by the PCR-based screening method for FXS (Table 1). Considering the total of 75 conclusive results by the PCR-based screening method for FXS, only five (6.7\%) of them did not match with those provided by SB (Table 1). The accuracy, sensitivity, and specificity were evaluated considering the results of the FXS alleles provided by PCR in contrast with those obtained by SB. That analysis of the efficiency of the Tassone et al. (2008) method for identifying the FXS alleles was performed in three different forms considering (1) all the 75 conclusive results by PCR (Fig. 4A); (2) the presence of NL and PM alleles by PCR (34 samples) (Fig. 4B); and (3) the presence of FM and NL alleles by PCR (44 samples) (Fig. 4C).

\section{Discussion}

In the present study, we assessed the accuracy, sensitivity, and specificity of the PCR-based screening method for FXS proposed by Tassone et al. (2008) in comparison with SB.

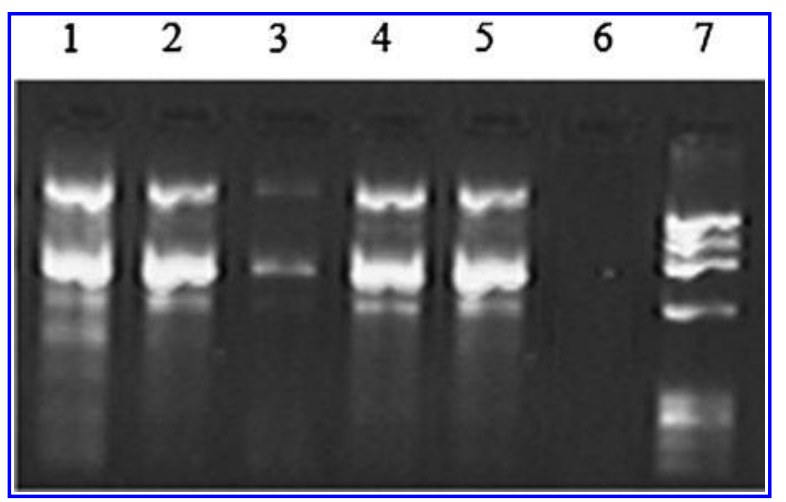

FIG. 2. A $2 \%$ agarose gel of second PCR products using the FastStart Taq DNA Polymerase. Lanes 1 and 2: Male subjects. Lanes 3 and 4: Female subjects, Lane 5: Female subject with NL alleles for FXS. Lane 6: Negative control. Lane 7: Molecular weight marker Phi X $174 \mathrm{HaeIII}$ (New England).

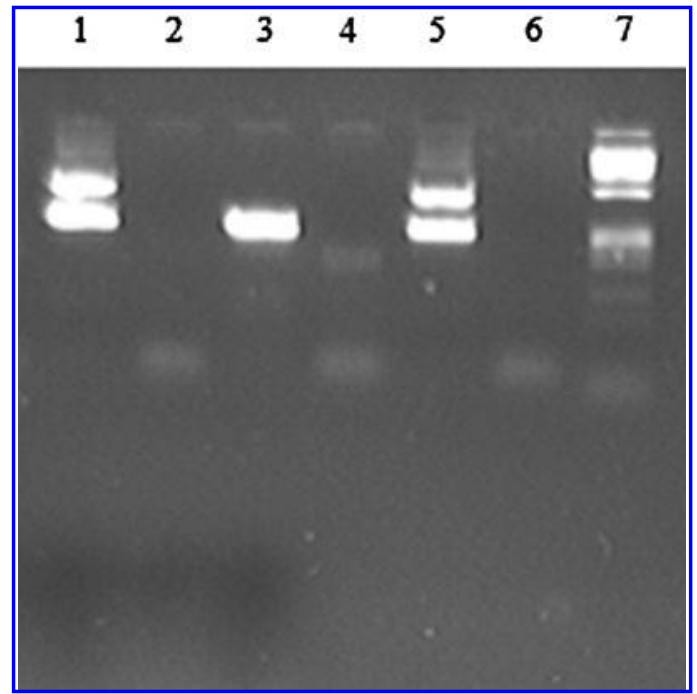

FIG. 3. A $2 \%$ agarose gel. Lanes 1, 3, and 5: Results of the first PCR (using the Expand Long Template PCR System). Lanes 2, 4, and 6: Results of the second PCR. Lanes 1, 2, 5, and 6: Female subjects carrying premutation (PM) alleles (in lane 1 and 5, PCR products confirmed the heterozygosity: NL and PM alleles; in lanes 2 and 6, PCR products do not appear, and this confirm the absence of expanded allele). Lanes 3 and 4: Female subject carrying NL allele (in lane 3, a single PCR product indicates homozygous for the NL allele; in lane 4, small PCR products are produced with the chimeric primer. This result confirmed the presence of only the NL allele). Lane 7: Molecular weight marker Phi X 174 HaeIII (New England).

To eliminate the hot start step, Tassone et al. (2008) utilized the FastStart Taq DNA polymerase enzyme, but in spite of many attempts, we were not able to reproduce the Tassone et al. (2008) secondary PCR, which is why we decided not to use this enzyme. Another study conducted by the Tassone group also used the FastStart Taq DNA polymerase, which demonstrated satisfactory results (Fernandez-Carvajal et al., 2009). Nevertheless, insufficient methodological details regarding the use of this enzyme were described. Although the authors stated that this method of PCR could detect all forms of FXS alleles, they continued looking for other molecular technologies to reach that objective. More recently, two different PCR methodologies were reported utilizing fluorescent primers and G-C-rich PCR reagents that were resolved by both capillary electrophoresis and agarose gel electrophoresis (Chen et al., 2010; Filipovic-Sadic et al., 2010).

Utilizing the Expand Long enzyme, we obtained 75 conclusive results from 78 individuals investigated. The three inconclusive results $(3.8 \%)$ occurred because there was no amplification in the second PCR. Therefore, they were excluded from this study.

Among the 75 conclusive results obtained by the PCRbased screening method, five $(6.7 \%)$ were not coincident with the SB diagnosis (Table 1). From those five samples, four samples were diagnosed as FM, because in the first PCR, there was no amplification of an allele in the range of the PM allele, and in the second PCR, an extensive smear was observed. Tassone et al. (2008) mentioned that this extensive smear indicates the presence of an FM allele. However, the SB analysis 
Table 1. Results of Both Polymerase Chain Reaction-Based Screening and Southern Blot Methods for Fragile X Syndrome Identification

\begin{tabular}{lllc}
\hline Number of individuals (\%) & Gender & PCR-based screening & Southern blot \\
\hline $01(1.3)$ & Male & NL (1st and 2nd PCRs) & NL \\
$02(2.5)$ & Female & NL (1st and 2nd PCRs) & NL \\
$10(12.8)$ & Male & PM (1st PCR) & PM \\
$02(2.5)$ & Male & FM (1st and 2nd PCRs) & PM \\
$20(25.7)$ & Female & PM (1st PCR) & PM \\
$02(2.5)$ & Female & FM (1st and 2nd PCRs) & PM \\
$26(33.4)$ & Male & FM (1st and 2nd PCRs) & FM \\
$11(14.1)$ & Female & FM (1st and 2nd PCRs) & FM \\
$01(1.3)$ & Male & PM (1st and 2nd PCRs) & PM and FM (mosaicism) \\
$03(3.9)$ & Female & Inconclusive (1st and 2nd PCRs) & FM \\
Total $78(100)$ & & &
\end{tabular}

PCR, polymerase chain reaction; NL, normal alleles; PM, premutation alleles; FM, full-mutation alleles.

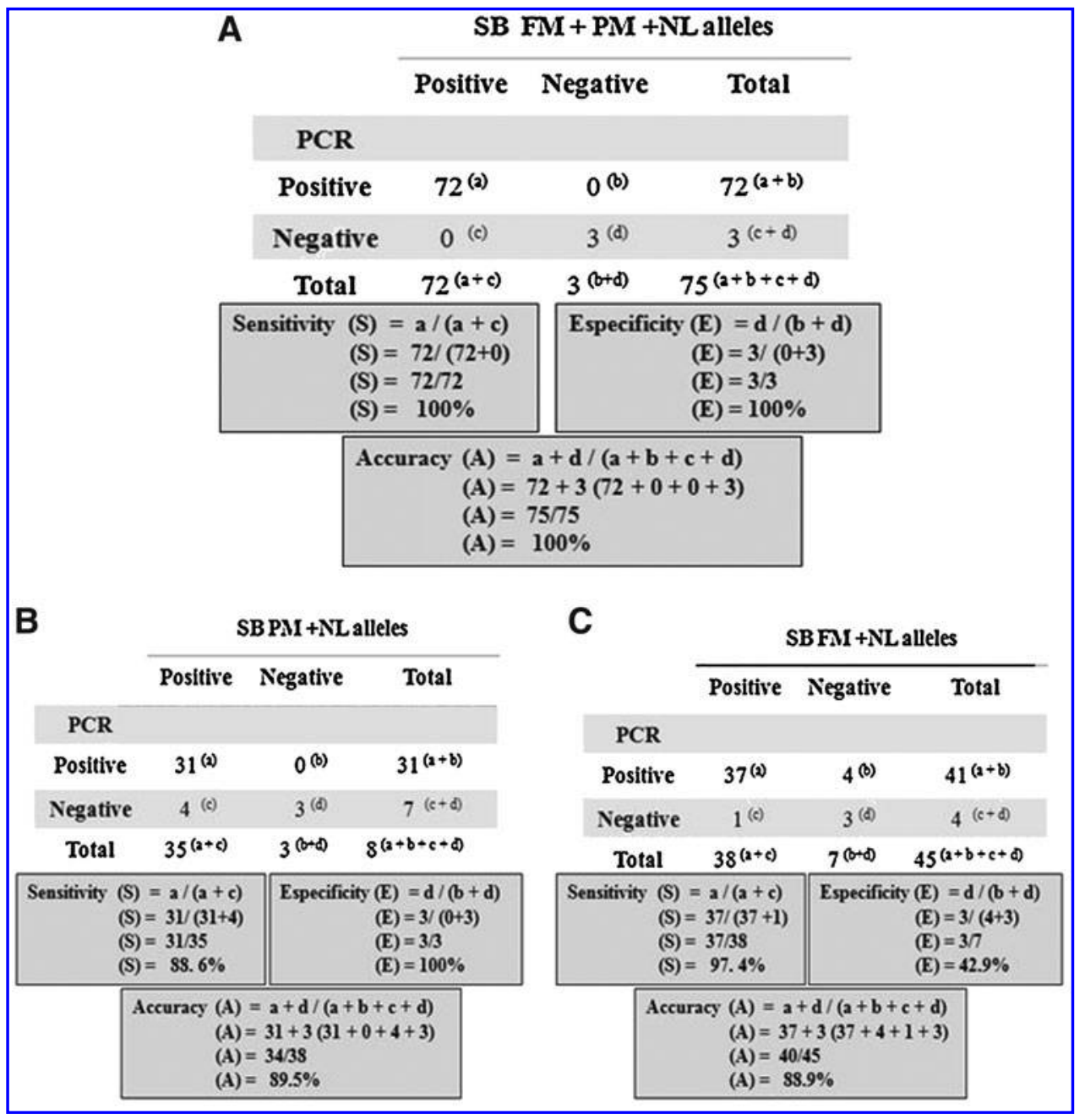

FIG. 4. Results of accuracy, sensitivity, and specificity. (A)—a: subjects carrying any FXS-expanded alleles detected by Southern blot (SB) that were also detected by the PCR (true positives); b: subjects that not carry FXS-expanded alleles detected by SB, but that were detected by the PCR (false-positive); c: subjects carrying any FXS-expanded allele detected by SB, which by the PCR they were not detected (false negative); d: subjects that not carry FXS-expanded alleles detected by SB, which were concordant by PCR (true negative); (B) — a: subjects that carry PM allele for FXS diagnosed by SB, and the PCR also diagnosed the PM allele (true positives); b: subjects that not carry PM allele for FXS by SB, but that PCR diagnosed PM allele (false positive); c: subjects that carry PM allele for FXS by SB and that PCR identify FM allele wrong (false-negative); d: subjects that not carry PM allele for FXS by SB, and that PCR not diagnosed none expanded allele (true negative); (C)—a: subjects that carry FM allele for FXS by SB and that PCR diagnosed this FM allele (true positive); b: subjects that not carry FM allele for FXS by SB, but that PCR method diagnosed FM allele (false positive); c: subject that carry FM allele for FXS by SB and that PCR method did not diagnose (false-negative); therefore, by PCR, this subject was identified only carrying of PM allele, without identifying the mosaicism; d: subjects that did not carry FM allele for FXS and that PCR did not diagnose none FM alleles (false negative). 
detected PM alleles in these four samples (Fig. 4B-c). According to Tassone et al. (2008), the PCR-based screening method for FXS identification is capable to detect in the first PCR the alleles in the upper range of PM ( 200 CGG repeats); nevertheless, even under conditions where the first PCR fail to detect a PM allele, the presence of such allele would be identified with the secondary PCR by the presence of an extensive smear. In those cases, the authors advised that SB should be used to definitively genotype the alleles. Therefore, it is understood that whenever there is the necessity of using the secondary PCR, and if the obtained results were an extensive smear, it is not possible to accurately distinguish between the PM or FM alleles (Tassone et al., 2008). One can hypothesize that the reason for using the PCR methodology demonstrated by Filipovic-Sadic et al. (2010) and Chen et al. (2010) would be to find a method capable to identifying the number of GCC repeats that are expanded, generating all the forms of FXS alleles.

Regarding the fifth sample investigated by a PCR-based screening method that was not coincident with SB, the first PCR was able to identify a PM allele. Nevertheless, by SB, the sample was genotyped as mosaic for the PM and FM alleles (Fig. 4C-c). Based on this result, we decided to perform a second PCR, and the presence of an expanded allele was confirmed by an extensive smear.

Because it is important to correctly diagnose FXS in individuals, SB is considered the gold-standard method and has been utilized since 1991 (Rousseau et al., 1991). However, as SB is a laborious and costly technique, numerous PCR-based procedures have been developed for rapid FXS screening (Haddad et al., 1996; Hamdan et al., 1997; Panagopoulos et al., 1999; Saluto et al., 2005; Dahl et al., 2007; Tassone et al., 2008). The screening methodological approaches should satisfy the principal requirements: to be rapid and cost effective (Fernandez-Carvajal et al., 2009). However, it is important to verify whether the FXS allele results provided by the developed approach are reliable. An elegant way to reach this is by calculating the accuracy, sensitivity, and specificity of the proposed approach and comparing their results with those obtained by another method considered the gold standard. Interestingly, in regard to FXS, only few previous studies were found presenting that focus. Rosales-Reynoso et al. (2007) compared 29 results obtained by methylation-specific PCR with the SB analysis and found sensitivity and specificity values of $100 \%$. High accuracy was found between the PCR method and SB, as reported by Filipovic-Sadic et al. (2010) and Chen et al. (2010). In the present study, comparing the Tassone et al. (2008) PCR-based screening method for FXS results with SB, when considering all types of FXS alleles (NL, PM, and FM), accuracy, sensitivity, and specificity demonstrated values of $100 \%$. This result proves that the PCR-based screening method is able to detect the presence of all the FXS alleles, similarly as concluded by Tassone et al. (2008). Considering only the PM and NL alleles in the analysis, sensitivity and accuracy decreased to $88.6 \%$ and $89.5 \%$, respectively (Fig. 4B). This occurred because that the PCR-based screening method failed to detect the real PM allele in four individuals that were incorrectly classified as FM (two men and two women, Table 1). The specificity remains at $100 \%$, probably because the PCR was able to find all the three individuals carrying the NL alleles. It is known that when a test demonstrates high specificity, the sensitivity decreases because there is a potential presence of false negatives (Sabbatini, 1995); in this case, the four PM alleles in the carriers were wrongly diagnosed by the PCR method as carriers of FM.

In the analysis performed on samples of subjects found as carrying the FM and NL alleles, besides sensitivity and accuracy, the specificity also decreased. The finding of four individuals who were found as FM allele carriers by the PCR method when they were actually carriers of PM alleles (by SB method, Fig. 4C-b) explains the specificity decrease. To show clear evidence, these individuals were the same represented in the Figure 4B-c. Similarly to this study, Filipovic-Sadic et al. (2010) also found that two individuals were found as FM carriers by the FMR1 PCR method, while they were scored as carriers of PM alleles by using the SB method. The authors mentioned that an analytical titration of FM and NL genomic DNA templates demonstrated that PCR is fivefold more sensitive than SB for detecting the FM allele. Considering this, and similarly the results obtained for the two individuals investigated by FilipovicSadic et al. (2010), we wonder if the four individuals tested here as PM allele carriers by the SB method could actually carry both PM and a low abundance of FM alleles. Perhaps, using the methodology described by Filipovic-Sadic et al. (2010) or Chen et al. (2010), this problem can be solved.

Moreover, the PCR method was not able to detect allelic mosaicism as we can see in the Figure 4C-c. It is worth keeping in mind that this analysis considered only the FM and NL alleles; therefore, a false-negative result happens when someone is not found as the FM allele carrier when, in fact, this allele is present (even if he/she carries a PM allele). This occurred with the mosaic subject investigated here, which resulted in the false-negative outcome, since this subject was only found to be as the carrier of the PM allele by the PCR method, while by SB, he was also an FM allele carrier.

In conclusion, we reproduced the PCR-based screening method for FXS reported by Tassone et al. (2008), using only the Expand Long Template PCR System Enzyme. Analyses of accuracy, sensitivity, and specificity of the PCR-based screening method in comparison with SB showed that the PCR methodology employed here was able to identify $100 \%$ of the different FXS alleles. However, the differentiation between PM and FM alleles was not accurate. The final results indicate that the PCR method is useful as a screening method for FXS and can be executed by any molecular biology laboratory, since it deserves conventional equipment. Nevertheless, SB is still the gold-standard method for the molecular diagnosis of FXS, because it is able to identify the number of CGG repeats and the methylation status.

\section{Acknowledgments}

We thank the patients and their relatives for their participation in this study. We also thank Ms. Renata de Aquino from the University Center of Araraquara (UNIARA) for her help in the initial step of this research.

\section{Author Disclosure Statement}

No competing financial interests exist.

\section{References}

Ayres M, Ayres Júnior M, Ayres DL, et al. (2007) BIOESTAT: Aplicações Estatísticas Nas Áreas Das Ciências Bio-Médicas. ONG Mamiraua, Belém. 
Chen L, Hadd A, Sah S, et al. (2010) An information-rich CGG repeat primed PCR that detects the full range of fragile $X$ expanded alleles and minimizes the need for southern blot analysis. J Mol Diagn 12:589-600.

Coffee B, Keith K, Albizua I, et al. (2009) Incidence of fragile X syndrome by newborn screening for methylated FMR1 DNA. Am J Hum Genet 85:503-514.

Crawford DC, Acuna JM, Sherman SL (2001) FMR1 and the fragile $\mathrm{X}$ syndrome: human genome epidemiology review. Genet Med 3:359-371.

Dahl C, Gronskov K, Larsen LA, et al. (2007) A homogeneous assay for analysis of FMR1 promoter methylation in patients with fragile X syndrome. Clin Chem 53:790-793.

Dodds ED, Tassone F, Hagerman PJ, Lebrilla CB (2009) Polymerase chain reaction, nuclease digestion, and mass spectrometry based assay for the trinucleotide repeat status of the fragile X mental retardation 1 gene. Anal Chem 81:5533-5540.

Fernandez-Carvajal I, Walichiewicz P, Xiaosen X, et al. (2009) Screening for expanded alleles of the FMR1 gene in blood spots from newborn males in a Spanish population. J Mol Diagn 11:324-329.

Filipovic-Sadic S, Sah S, Chen L, et al. (2010) A novel FMR1 PCR method for the routine detection of low abundance expanded alleles and full mutations in fragile $\mathrm{X}$ syndrome. Clin Chem 56:399-408.

Fu YH, Kuhl DP, Pizzuti A, et al. (1991) Variation of the CGG repeat at the fragile $X$ site results in genetic instability: resolution of the Sherman paradox. Cell 67:1047-1058.

Haddad LA, Mingroni-Netto RC, Vianna-Morgante AM, Pena SD (1996) A PCR-based test suitable for screening for fragile $X$ syndrome among mentally retarded males. Hum Genet 97:808-812.

Hagerman PJ, Hagerman RJ (2004) Fragile X-associated tremor/ ataxia syndrome (FXTAS). Ment Retard Dev Disabil Res Rev 10:25-30.

Hagerman RJ, Rivera SM, Hagerman PJ (2008) The fragile X family of disorders a model for autism and targeted tratments. Curr Pedriatr Rev 4:12.

Hamdan H, Tynan JA, Fenwick RA, Leon JA (1997) Automated detection of trinucleotide repeats in fragile x syndrome. Mol Diagn 2:259-269.

Mingroni-Netto RC, Haddad LA, Vianna-Morgante AM (1996) The number of CGG repeats of the FMR1 locus in premutated and fully mutated heterozygotes and their offspring: implications for the origin of mosaicism. Am J Med Genet 64: 270-273.

Panagopoulos I, Lassen C, Kristoffersson U, Aman P (1999) A methylation PCR approach for detection of fragile $X$ syndrome. Hum Mutat 14:71-79.

Rosales-Reynoso MA, Vilatela EA, Ojeda RM, et al. (2007) PCR approach for detection of Fragile $\mathrm{X}$ syndrome and Huntington disease based on modified DNA: limits and utility. Genet Test 11:153-159.

Rousseau F, Heitz D, Biancalana V, et al. (1991) Direct diagnosis by DNA analysis of the fragile $\mathrm{X}$ syndrome of mental retardation. N Engl J Med 325:1673-1681.

Sabbatini RME (1995) Um programa para cálculo da acurácia, especificidade e sensibilidade de testes médicos. Rev Inform 2:3.

Saluto A, Brussino A, Tassone F, et al. (2005) An enhanced polymerase chain reaction assay to detect pre- and full mutation alleles of the fragile $\mathrm{X}$ mental retardation 1 gene. $\underline{\mathrm{IMol}}$ Diagn 7:605-612.

Sofocleous C, Kolialexi A, Mavrou A (2009) Molecular diagnosis of Fragile X syndrome. Expert Rev Mol Diagn 9:23-30.

Tassone F, Pan R, Amiri K, et al. (2008) A rapid polymerase chain reaction-based screening method for identification of all expanded alleles of the fragile X (FMR1) gene in newborn and high-risk populations. J Mol Diagn 10:43-49.

Verkerk AJMH, Pieretti M, Sutcliffe JS, et al. (1991) Identification of a gene (FMR-1) containing a CGG coincident with breakpoint cluster region exhibiting length variation in fragile $X$ syndrome. Cell 65:905-914.

Address correspondence to: Raquel Mantuaneli Scarel-Caminaga, Ph.D. Departamento de Morfologia Faculdade de Odontologia de Araraquara

UNESP

Univ Estadual Paulista Campus Araraquara Rua Humaitá 1680 14.801-903 Araraquara-SP Brazil

E-mail: raquel@foar.unesp.br 